\title{
Thyroid Ultrasound Reports: Deficiencies and Recommendations
}

\author{
Laila Qadan $^{\mathrm{a}}$ Adel Ahmed $^{\mathrm{b}}$ Kusum Kapilac \\ ${ }^{a}$ Department of Medicine, Faculty of Medicine, Kuwait University, Jabriya, Kuwait; ${ }^{b}$ Department of Radiology, \\ Faculty of Medicine, Kuwait University, Jabriya, Kuwait; ' ${ }^{D}$ Department of Pathology, Faculty of Medicine, \\ Kuwait University, Jabriya, Kuwait
}

\section{Significance of the Study}

- Thyroid ultrasound plays a major role in the clinical management of adult patients with thyroid nodules. Its role is greatly dependent on the operator's experience and comprehensive reporting. In this study, we aimed at an objective evaluation of the content and completeness of thyroid radiology reports. Incomplete ultrasound reports ultimately affect malignant risk stratification and subsequent therapeutic decisions.

\section{Keywords}

Ultrasound report · Thyroid ultrasound · Thyroid nodule · Risk assessment

\footnotetext{
Abstract

Objective: Thyroid ultrasound plays a major role in the clinical management of patients with thyroid nodules. Comprehensive reporting enables malignant risk stratification and biopsy decisions. In this study, we aimed at a systematic evaluation of the content and completeness of thyroid radiology reports. Methods: A retrospective study was undertaken. A total of 200 thyroid ultrasound reports of examinations performed over a 1-year period were reviewed. After excluding 18 reports, the remaining 182 were evaluated for the inclusion of the following nodule characteristics: size, 3-axis dimensions, location, presence or absence of five signs suspicious of malignancy, namely microcalcification, hypoechogenecity, irregular margin, height-to-width ratio, and
}

intranodular vascularity. Results: While all reported nodules could be stratified easily as being more or less than $1 \mathrm{~cm}$ in size, only $23.6 \%$ of these nodules were reported in 3 dimensions, and $33.5 \%$ of the nodules were specifically localized. For any described nodule, the frequency of reporting on echogenicity was $50 \%$, on vascularity $19.2 \%$, on margin $10.4 \%$, on calcifications $9.3 \%$, and no report contained a description of the height-to-width ratio. The cumulative frequency of reporting on one characteristic per nodule was $84 \%$, of two characteristics $27 \%$, three characteristics $4.4 \%$, and no report included $\geq 4$ characteristics per nodule. Conclusion: Despite easily accessible templates, reporting of thyroid nodule sonogram continues to be incomplete and inconsistent. This in turn constitutes a waste of a significant tool that could otherwise help in making timely informed medical decisions and in providing a significant platform for patients' future follow-up.

(C) 2019 The Author(s)

Published by S. Karger AG, Basel

\begin{tabular}{ll}
\hline KARGER & $\begin{array}{l}\text { @ } 2019 \text { The Author(s) } \\
\text { Published by S. Karger AG, Basel Openger }\end{array}$ \\
$\begin{array}{l}\text { E-Mail karger@karger.com } \\
\text { www.karger.com/mpp }\end{array}$ & $\begin{array}{l}\text { This is an Open Access article licensed under the Creative Commons } \\
\text { Attribution-NonCommercial-4.0 International License (CC BY-NC) } \\
\text { (http://www.karger.com/Services/OpenAccessLicense), applicable to } \\
\text { the online version of the article only. Usage and distribution for } \\
\text { commercial purposes requires written permission. }\end{array}$
\end{tabular}

Laila Qadan

Department of Medicine, Faculty of Medicine, Kuwait University PO Box 24923

Safat 13110 (Kuwait)

E-Mail laila@ @sc.edu.kw 


\section{Introduction}

Thyroid nodules are commonly detected by high-resolution ultrasound with a prevalence of $19-67 \%$ [1]. While most of these nodules are benign, thyroid cancer is found in $5-15 \%$ of cases [2]. Therefore, their clinical significance relies on the ability to discriminate between benign and malignant lesions. As the likelihood of malignancy is greatly influenced by sonographic features, ultrasound has proven to be a significant tool in the initial evaluation, malignant risk stratification, and long-term management of thyroid nodules, thus its use has been endorsed by the American Thyroid Association (ATA), American Association of Clinical Endocrinologists (AACE), and European Thyroid Association [1-4]. The key role it plays in making clinical decisions is highly dependent on informative, easily interpreted reports provided by experienced, knowledgeable physicians.

Over history, the domain of ultrasound has moved gradually from being completely controlled by radiologists to being shared with clinicians, a move that could be related in part to inefficient communication of abnormalities detected by ultrasound to treating physicians [5]. Efforts to decrease the ambiguity of thyroid ultrasound reports and enhance their diagnostic value have persisted for years. Tools to standardize reporting have been developed such as the Thyroid Imaging Reporting and Data System (TIRADS) by Horvath et al. [6], and then modified by others over the last decade [1,3,5-14]. Additionally, the ATA and AACE guidelines provide specific features that should, at a minimum, be documented in reports $[1,3]$. All these guidelines, differences notwithstanding, agree on the principle that all thyroid ultrasound reports should explicitly describe features that inform decision-making. To date, and despite these efforts, the general adoption of any comprehensive reporting tool seems to be a challenge, and reporting in many instances continues to follow subjective personal preferences.

There is limited research that critically appraises the content of the ultrasound reports provided by radiologists. Few studies have documented the suboptimal quality at some centers, in addition to a widespread dissatisfaction by endocrinologists and surgeons with these reports [15-20]. The negative impact of incomplete reporting on timely cytological diagnosis and surgical intervention has been documented [19, 20]. Nevertheless, Griffin et al. [21] proved recently, in a three-phase study, that simple implementation of the ACR TI-RADS structured reporting template improved the quality significantly. Therefore, more studies are required to continu- ously and objectively evaluate the value of these reports at different facilities. This in turn will eventually, in collaboration with the relentless efforts made by different organizations to standardize and simplify the reporting, induce the change.

At our center, thyroid ultrasound has been performed primarily by radiologists for years; anecdotal experience seemed to be frustrating at multiple occasions due to the lack of significant information in the supplemented reports. In this study, we retrospectively reviewed 182 reports done over a 1-year period, aiming at an objective evaluation of their content and completeness.

\section{Methods}

We conducted a retrospective evaluation of 200 thyroid ultrasound reports of studies performed by radiologists at a tertiary referral medical center in Kuwait between March 2014 and April 2015. After excluding reports that showed no discrete lesions and those that reported purely cystic nodules, a total of 182 reports of thyroid nodules were finally reviewed. The study was conducted in accordance with our institution's research ethics guidelines.

Using some of the guidelines of ATA and AACE on assessment of thyroid nodules, each report was assessed for the inclusion of the following criteria: size of nodule(s), 3-axis dimensions, meticulous localization, presence or absence of five signs suspicious of malignancy, namely microcalcification, hypoechogenecity, irregular margin, height-to-width ratio, and intranodular vascularity $[1,3]$.

The size of the nodule was stratified to be above or below $1 \mathrm{~cm}$ based on the largest diameter. Location was evaluated as being nonspecific (simply the lobe) or more descriptive (as lower pole, upper pole, or central). Other features were considered recorded if they were specifically reported as being present or absent.

\section{Statistical Analysis}

All statistical analyses were conducted using SPSS software. Analyses included $\chi^{2}$ and Fisher's exact test to study the association between the variables. The results were considered statistically significant at $p<0.05$. Number, frequencies, and percentages were also calculated.

\section{Results}

A total of $58.8 \%$ of the 182 reports reviewed were of multinodular glands ( $>1$ nodule), and $41.2 \%$ were of glands with unifocal lesions. As for multiple nodular goiters, $76.6 \%$ of the reports referred only to the largest nodule, $1.9 \%$ reported suspicious looking nodules, $12.1 \%$ reported on all nodules, and $9.3 \%$ reported on none. A total of $65.4 \%$ of the nodules reported were $\geq 1 \mathrm{~cm}$ in size. A nonspecific description of the location (only specifying the lobe) was the case in $66.5 \%$ of all nodules. Only $23.6 \%$ 
of nodules were reported in 3 dimensions; this was not significantly influenced by nodule size being more or less than $1 \mathrm{~cm}(p=0.073)$; however, it was significantly more likely to be reported for single rather than multiple nodular goiters $(p<0.001)$.

For any described nodule, the frequency of reporting on echogenicity was $50 \%$, on vascularity $19.2 \%$, on margin $10.4 \%$, on calcifications $9.3 \%$, and no report contained description of the height-to-width ratio. For those reported, the cumulative frequency of reporting on one characteristic per nodule was $84 \%$, two characteristics $27 \%$, three characteristics $4.4 \%$, and no report included $\geq 4$ characteristics per nodule. Furthermore, $34.6 \%$ of the reports mentioned none of the five characteristics.

Echogenicity and vascularity were more likely to be reported $(p<0.001)$ for single rather than multiple nodular goiters. However, that difference was not significant for calcifications and margin reporting, respectively $(p=$ 0.299 and $p=0.285$ ).

While nodular size made no significant difference in reporting on margin $(p=0.215)$, echogenicity $(p=0.275)$, or calcification $(p=0.951)$, vascularity was significantly more reported on nodules $\geq 1 \mathrm{~cm}(p<0.001)$.

Out of all nodules with reported echogenicity, $42.9 \%$ were hypoechogenic $(p<0.001)$, out of those with reported calcifications, $47.1 \%$ were positive for microcalcification $(p<0.001)$, and $82.9 \%$ of those with reported vascularity had increased intranodular vascularity $(p<0.001)$. Finally, $5.3 \%$ of reported margins were irregular $(p=0.104)$.

\section{Discussion}

In this study aiming to evaluate the content of ultrasound reports for thyroid nodules, we found that reports lacked standardization and consistency. In most cases, the description was suboptimal to guide a subsequent clinical decision on management or even a proper baseline for future follow-up. Our study is in agreement with others showing that few thyroid ultrasound reports contained the necessary information, and greatly supports previous studies expressing dissatisfaction of physicians with reports provided by radiologists [15-20].

Ultrasound is a primary tool in the evaluation, risk stratification, and follow-up of thyroid nodules. However, its value in impacting diagnosis and thus therapeutic decisions is highly affected by the operator and style of reporting. For example, malignant risk stratification using ATA guidelines would be significantly impeded by suboptimal documentation. This is evidenced by a tre- mendous rise in the estimated risk of malignancy for a solid hypoechoic nodule from $10-20 \%$ to $>70-90 \%$ if at least one additional feature, such as microcalcification, taller-than-wide shape, or irregular margin, was reported as absent or present, respectively [1]. Therefore, commenting on echogenicity in addition to other suspicious malignant features should be complementary and not mutually exclusive. Furthermore, since different studies favored different criteria as better predictors of malignan$\mathrm{cy}$, the more features reported the better is the distinction between benign and malignant lesions $[1-3,13,14,17,19$, 20]. In our study, the low rate of reporting on each of the suspicious malignant features and even lower cumulative reporting on multiple criteria is quite worrisome.

As for patients with multiple thyroid nodules, the ATA recommends that each nodule $\geq 1 \mathrm{~cm}$ should be evaluated in the same fashion as a solitary nodule $\geq 1 \mathrm{~cm}$, since each of these nodules carries an independent risk of malignancy [1]. Additionally, the ACR TI-RADS Committee discourages the usage of the term "dominant nodule," as it underestimates the primary role of architecture in determining further management [14]. Hence, the choice of reporting solely on the largest nodule, which seems to be largely adopted at our center, would by default ignore other possibly suspicious nodules that could require immediate attention and/or close follow-up on serial ultrasounds.

Follow-up of thyroid nodules using serial sonograms is done to determine nodular growth and/or change in pattern. This in turn is meant to guide future FNA decision-making based on either a $20 \%$ increase in at least two of the three nodular dimensions and/or development of suspicious US characteristics [1, 14, 22, 23]. Therefore, an initial precisely descriptive platform report that includes three axis dimensions and specific localization of any nodule targeted for follow-up is extremely essential for serial comparison, and its value cannot be overstated [14]. In turn, the paucity of this essential information in our reports further highlights their suboptimal nature.

The solution is within reach and is evidenced by the recent study by Griffin et al. [21]. They compared the completeness and consistency of thyroid ultrasound reports before and after the implementation of the ACR TIRADS and concluded that the use of a structured reporting template improved the quality of these reports significantly [21].

Limitations of our study include the small sample size and the retrospective nature of the study. Furthermore, it lacked data on the clinical outcome that could have been affected by the quality of thyroid ultrasound reports. Larger prospective studies are warranted. 


\section{Conclusion}

The pivotal role that thyroid ultrasound plays in the management of patients with thyroid nodules necessitates applying standardized reporting system templates such as the ACR TI-RADS. The role of a thorough, informative, and easily interpreted report which is not based on subjective preference is indispensable for the utilization of ultrasound in the management of patients.

\section{Acknowledgements}

We gratefully acknowledge the help of Dr. Amro Elmoursi and Mr. Ahmed Mohammed in collecting the data and the statistical analysis, respectively.

\section{Disclosure Statement}

The authors have no conflicts of interest to disclose.

\section{References}

1 Haugen BR, Alexander EK, Bible KC, Doherty GM, Mandel SJ, Nikiforov YE, et al. 2015 American Thyroid Association Management guidelines for adult patients with thyroid nodules and differentiated thyroid cancer nodules and differentiated thyroid cancer. Thyroid. 2016 Jan;26:1-133.

2 Remonti LR, Kramer CK, Leitão CB, Pinto LC, Gross JL. Thyroid ultrasound features and risk of carcinoma: a systematic review and meta-analysis of observational studies. Thyroid. 2015 May;25(5):538-50.

3 Gharib H, Papini E, Garber JR, Duick DS, Harrell RM, Hegedüs L, et al.; AACE/ACE/ AME Task Force on Thyroid Nodules. AACE/ ACE/AME Task Force on Thyroid Nodules: American Association of Clinical Endocrinologists, American College of Endocrinology, and Associazione Medici Endocrinologi medical guidelines for clinical practice for the diagnosis and management of thyroid nodules - 2016 update. Endocr Pract. 2016 May; 22(5):622-39.

4 Russ G, Bonnema SJ, Erdogan MF, Durante C, Ngu R, Leenhardt L. European Thyroid Association Guidelines for Ultrasound malignancy risk stratification of thyroid nodules in adults: the EU-TIRADS. Eur Thyroid J. 2017 Sep;6(5):225-37.

5 Bosmans JM, Peremans L, De Schepper AM, Duyck PO, Parizel PM. How do referring clinicians want radiologists to report? Suggestions from the COVER survey. Insights Imaging. 2011 Oct;2(5):577-84.

6 Horvath E, Majlis S, Rossi R, Franco C, Niedmann JP, Castro A, et al. An ultrasonogram reporting system for thyroid nodules stratifying cancer risk for clinical management. J Clin Endocrinol Metab. 2009 May;94(5):1748-51.

7 Russ G. Risk stratification of thyroid nodules on ultrasonography with the French TIRADS: description and reflections. Ultrasonography. 2016 Jan;35(1):25-38.
8 Na DG, Baek JH, Sung JY, Kim JH, Kim JK, Choi YJ, et al. Thyroid imaging reporting and data system risk stratification of thyroid nodules: categorization based on solidity and echogenicity. Thyroid. 2016 Apr;26(4):56272.

9 Su HK, Dos Reis LL, Lupo MA, Milas M, Orloff LA, Langer JE, et al. Striving toward standardization of reporting of ultrasound features of thyroid nodules and lymph nodes: a multidisciplinary consensus statement. Thyroid. 2014 Sep;24(9):1341-9.

10 Zhou H, Yue WW, Du LY, Xu JM, Liu BJ, Li $\mathrm{XL}$, et al. A modified thyroid imaging reporting and data system (mTI-RADS) for thyroid nodules in coexisting Hashimoto's thyroiditis. Sci Rep. 2016 May;6(1):26410.

11 Sanchez JF. TI-RADS classification of thyroid nodules based on a score modified according to ultrasound criteria for malignancy. Rev Argent Radiol. 2014;78:138-48.

12 Andrioli M, Carzaniga C, Persani L. Standardized ultrasound report for thyroid nodules: the endocrinologist's viewpoint. Eur Thyroid J. 2013 Mar;2(1):37-48.

13 Grant EG, Tessler FN, Hoang JK, Langer JE, Beland MD, Berland LL, et al. Thyroid ultrasound reporting lexicon: white paper of the ACR thyroid imaging, reporting and data system (TIRADS) committee. J Am Coll Radiol. 2015 Dec;12(12 12 Pt A):1272-9.

14 Tessler FN, Middleton WD, Grant EG, Hoang JK, Berland LL, Teefey SA, et al. ACR Thyroid imaging, reporting and data system (TIRADS): white paper of the ACR TI-RADS committee. J Am Coll Radiol. 2017 May; 14(5):587-95.

15 Rowe ME, Osorio M, Likhterov I, Urken ML. Evaluation of ultrasound reporting for thyroid cancer diagnosis and surveillance. Head Neck. 2017 Sep;39(9):1756-60.
16 Claassens S, Mitchell C, Hlabangana T. Quality assessment of thyroid ultrasound and implementation of a standard reporting template to be used in training hospitals. S Afr J Rad. 2017;21(1):a1125.

17 Gamme G, Parrington T, Wiebe E, Ghosh S, Litt B, Williams DC, et al. The utility of thyroid ultrasonography in the management of thyroid nodules. Can J Surg. 2017 Apr;60(2): 134-9.

18 Bajaj H, Nawaz M, Chadha A. Canadian endocrinologists are not satisfied with radiology reporting of diagnostic neck ultrasound and US-guided fine needle aspiration of thyroid nodules (survey report). Can J Diabetes. 2014; 38(5):S39.

19 Inman A, Liu K, Ong K, Tiwari P, Vos $\mathrm{P}$, White A, et al. Completeness of ultrasound reporting impacts time to biopsy for benign and malignant thyroid nodules. Am J Surg. 2017 May;213(5):931-5.

20 Karkada M, Costa AF, Imran SA, Hart RD, Bullock M, Ilie G, et al. Incomplete thyroid ultrasound reports for patients with thyroid nodules: implications regarding risk assessment and management. AJR Am J Roentgenol. 2018 Dec;211(6):1348-53.

21 Griffin AS, Mitsky J, Rawal U, Bronner AJ, Tessler FN, Hoang JK. Improved quality of thyroid ultrasound reports after implementation of the ACR Thyroid imaging reporting and data system nodule lexicon and risk stratification system. J Am Coll Radiol. 2018 May; 15(5):743-8.

22 Brauer VF, Eder P, Miehle K, Wiesner TD, Hasenclever H, Paschke R. Interobserver variation for ultrasound determination of thyroid nodule volumes. Thyroid. 2005 Oct; 15(10):1169-75.

23 Choi YJ, Baek JH, Hong MJ, Lee JH. Interobserver variation in ultrasound measurement of the volume and diameter of thyroid nodules. Korean J Radiol. 2015 May-Jun; 16(3):560-5. 